\title{
Eficiência de isolados de Trichoderma spp no controle de patógenos de solo em meloeiro amarelo ${ }^{1}$
}

\author{
Efficiency of Trichoderma sp isolates on the control of soil-borne pathogens in the \\ yellow melon
}

\author{
Carlos Alberto Tuão Gava ${ }^{2 *}$ e Michelly Elen Leal Menezes ${ }^{3}$
}

\begin{abstract}
RESUMO - Patógenos oriundos do solo têm se tornado uma forte limitação ao cultivo do meloeiro nas condições edafoclimáticas predominantes no Vale do Submédio São Francisco. Uma vez que o controle deste grupo de patógenos utilizando fungicidas tem se mostrado pouco eficiente, se faz necessário o desenvolvimento de alternativas que possam ser aplicadas ao manejo integrado das doenças causadas por estes patógenos. Com este objetivo, quatro isolados de Trichodema spp. foram avaliados quanto a habilidade para a colonização da rizosfera do meloeiro em condições controladas e a sua eficiência de controle de patógenos em condições de campo. Os experimentos foram realizados utilizando sementes de meloeiro tratadas com uma formulação de conídios dos fungos T. harzianum LCB47, T. viridae LCB48, T. koningii LCB49 e T. polysporum LCB50. Nas condições experimentais, os tratamentos LCB47, LCB48 e LCB49 apresentaram contagem de propágulos na rizosfera estatisticamente similares entre si (de 4,54; 5,81 e 5,66 $\log _{10} \mathrm{UFC} \mathrm{g}^{-1}$ de raiz, respectivamente) e significativamente superior ao LCB50 $\left(3,21 \log _{10} \mathrm{UFC} \mathrm{g}^{-1} \mathrm{de} \mathrm{raiz}_{\text {) }}\right.$. Em experimento de campo verificou-se que os tratamentos inoculados com os isolados LCB49 e LCB50 apresentaram incidência de doença similar entre si (24,7 e 28,6\% de plantas sintomáticas, respectivamente) e eficácia de controle superior aos demais. Estes tratamentos resultaram em maior número de plantas no estande ao final do experimento e, consequentemente, em maior produtividade de frutos. Assim, conclui-se que os isolados T. koningii LCB49 e T. polysporum LCB50 apresentam potencial para uso no controle biológico de patógenos de solo do meloeiro no Vale do São Francisco.
\end{abstract}

Palavras-chave: Melão. Patógenos de solo. Controle biológico. Biofungicidas.

\begin{abstract}
Soil borne pathogens have become a strong limitation to the cultivation of melons under the edaphicclimatic conditions prevailing in the sub-medium San Francisco River valley. Since control of this group of pathogens using fungicides hás been ineffective, it is necessary to develop alternatives that can be applied to the integrated management of diseases caused by these pathogens. To this end, four isolates of Trichodema sp. were evaluated for their ability to colonise the rhizosphere of melon plants under controlled conditions, and their efficiency in the control of pathogens under field conditions. The experiments were carried out using melon seeds treated with formulations of conidia of the fungi $T$. harzianum LCB47, T. viridae LCB48, T. koningii LCB49 and T. polysporum LCB50. Under the experimental conditions, the treatments LCB47, LCB48 and LCB49 presented propagule counts in the rhizosphere, statistically similar to one another (of 4.54, 5.81 and $5.66 \log _{10}$ CFU g ${ }^{-1}$ root, respectively) and significantly higher than LCB50 (3.21 $\log _{10} \mathrm{CFU} \mathrm{g}^{-1}$ root). In the field experiment, it was found that the treatments inoculated with the isolates LCB50 and LCB49, showed an incidence of disease similar to each other ( 24.7 and $28.6 \%$ of symptomatic plants, respectively) and a greater effective control than the others. These treatments resulted in a larger number of plants in the planter at the end of the experiment and a consequently higher fruit yield. Thus, it can be concluded that the isolates, T. koningii LCB49 and T. polysporum LCB50, show potential for use in the biological control of soil pathogens in the melon in the San Francisco River valley.
\end{abstract}

Key words: Melon. Soil borne pathogens. Biological control. Biofungicides.

\footnotetext{
*Autor para correspondência

${ }^{1}$ Recebido para publicação em 02/08/2011; aprovado em 15/03/2012

Projeto de pesquisa có-financiado pela Empresa Brasileira de Pesquisa Agropecuária/EMBRAPA e pelo Fundo de Desenvolvimento Científico do Banco do Nordeste do Brasil - BNB-FUNDECI

${ }^{2}$ Laboratório de Controle Biológico, Embrapa Semiárido, BR 428, Km 152, Zona Rural, Caixa Postal 23, Petrolina-PE, Brasil, 56.302-970, gava@cpatsa.embrapa.br

${ }^{3}$ Bolsista CNPQ, Embrapa Semiárido, BR 428, Km 152, Zona Rural, Caixa Postal 23, Petrolina-PE, Brasil, 56.302-970, melmenezes@ gmail.com
} 


\section{INTRODUÇÃO}

Patógenos de plantas oriundos do solo têm se tornado uma forte limitação ao cultivo do meloeiro nas condições edafoclimáticas predominantes no Vale do Rio São Francisco. Doenças fúngicas como o cancro-dashastes (Dydimella bryonae (Fuckel) Rehm.), podridãobranca (Macrophomina phaseolina (Tassi) Goidanich.), murcha de Sclerotium (Sclerotium rolfsii Sacc.), murchade-fusarium (Fusarium oxysporum f.sp. melonis Snyder \& Hansen) e podridão radicular de fusarium ( $F$. solani (Mart.) Sacc.) têm causado severa redução da produtividade (Medeiros et al., 2006; Tavares, 2001). O cultivo sucessivo, o manejo inadequado da água de irrigação, a manutenção de resíduos de cultura no campo e a ausência de rotação de culturas aumentaram a incidência e a severidade das doenças e o uso de fungicidas convencionais não tem apresentado proteção efetiva contra este grupo de patógenos. Neste contexto, o uso de agentes microbianos é uma das alternativas a serem utilizadas para o controle destes fitopatógenos. No entanto, embora inúmeros microrganismos tenham sido apontados como antagonistas a patógenos oriundos do solo, poucos evoluíram para uso em escala comercial (HARMAN et al., 2010). As falhas mais comuns se referem às performances inconsistentes em condições de campo, interferência de variáveis edafoclimáticas sobre a eficiência de controle e atividade sobre limitado número de patógenos (BUTT; JACKSON; MAGAN, 2001; CHINCHOLKAR; MUDERJI, 2007).

A competência rizosférica de um possível agente de controle biológico (ACB), ou seja, sua capacidade em colonizar a espermosfera de sementes e a rizosfera das plantas, lhe confere uma grande vantagem competitiva em relação a microrganismos autóctones e patógenos radiculares (McLEAN et al., 2005; WEERT; BLOEMBERG, 2006; WHIPPS, 2001). A ausência da competência rizosférica, contudo, não restringe a eficiência do ACB se a supressão de patógenos se dá pela destruição de propágulos no solo ou em restos de cultivo. No entanto, tem sido demonstrado que ACBs competentes para a colonização da rizosfera apresentam maior eficácia de controle (EL-TARABILLI, 2006; MIRANDA; ESTRELLA; CABRIALESA, 2006).

As espécies de fungos do gênero Trichoderma são os ACBs mais estudados para o controle de patógenos oriundos do solo ou parte aérea, em condições de campo e em cultivo protegido, com aplicação tanto em pré quanto pós-colheita (UBALUA; OTTI, 2007, HARMAN, 2006). Os seus mecanismos de ação envolvem a lise celular produzida por enzimas como quitinase, proteases e glucanases (HARMAN, 2006), indução de resistência (YEDIDIA et al., 2003) e produção de antibióticos (EL-HASAN; WALKER; BUCHENAVER, 2006; ZaYeD; ABDEL-MOTAAL, 2005).
Em trabalhos anteriores, realizados no Pólo Petrolina/Juazeiro, demonstrou-se o potencial do uso de fungos do gênero Trichoderma no controle de patógenos de solo nas culturas de tomate, maracujá, feijão-caupi e melancia (BATISTA et al., 2002, TAVARES et al., 1999), resultando na seleção de isolados promissores. Este trabalho teve como objetivos avaliar a competência rizosférica dos fungos $T$. harzianum LCB47, $T$. viridae LCB48, T. koningii LCB49 e $T$. polysporum LCB50 em meloeiro amarelo e a sua eficiência de controle de doenças em área de cultivo naturalmente infestada no Vale do São Francisco, utilizando tratamentos de sementes com uma formulação em pó-molhável adesiva.

\section{MATERIAL E MÉTODOS}

Nestes estudos foram utilizados os isolados Trichoderma harzianum LCB47, T. viride LCB48, T. koningii LCB49, T. polysporum LCB50, mantidos na coleção de microrganismos da Embrapa Semiárido (Tabela 1). Os isolados foram armazenados segundo o método de Castellani e repicados em placas de Petri contendo meio Batata Dextrose Agar (BDA) e mantidos em BOD a $28 \pm 0,2^{\circ} \mathrm{C}$ por 15 dias. A identificação dos isolados de Trichoderma foi confirmada pela análise de carácteres morfológicos de colônias obtidas em cultivo monospórico, conforme Samuels et al. (2008). Após esse período, uma suspensão de conídios em Triton X-100 0,05\% foi obtida por raspagem das colônias. As suspensões foram padronizadas a $10^{8}$ conídios $\mathrm{mL}^{-1}$ e uma alíquota de $2 \mathrm{~mL}$ foi transferida para sacos plásticos contendo $200 \mathrm{~g}$ de arroz parbolizado autoclavado contendo $40 \%$ de umidade. Os sacos foram mantidos em câmara de incubação $\left(28 \pm 2{ }^{\circ} \mathrm{C}\right)$ por 10 dias, período em que se observou intensa esporulação. Após a esporulação, o arroz colonizado foi transferido para câmara de secagem a $30 \pm 2{ }^{\circ} \mathrm{C}$. Após a secagem, os conídios foram extraídos utilizando-se um extrator de conídios Mycoharvester M5 (ACIS R\&D, Devon, UK). A viabilidade dos conídios ao final do processo foi determinada transferindo-se $100 \mu \mathrm{l}$ de uma suspensão de $10^{5}$ conídios $\mathrm{mL}^{-1}$ para placas de Petri de $4,5 \mathrm{~cm}$ contendo meio BDA. Após doze horas, verificou-se a taxa de germinação de conídios realizando-se contagem em cinco campos em microscopio ótico com aumento de 400 vezes, totalizando pelo menos 300 conídios. Os conídios foram considerados germinados quando o tubo germinativo apresentava comprimento igual o superior ao seu diâmetro.

Sementes de meloeiro amarelo híbrido AF 682 (Sakata Seeds Sudamerica Ltda) foram inoculadas com uma formulação em pó-molhável adesiva, com $10^{8}$ conídios de Trichoderma $\mathrm{mL}^{-1}$. Os isolados utilizados nos 
Tabela 1 - Identificação dos tratamentos e caracterização dos isolados de Trichodema spp. utilizados nos experimentos

\begin{tabular}{lcc}
\multicolumn{1}{c}{ Tratamentos } & Identificação original & Coleção de Origem \\
\hline T. harzianum LCB47 & T15 & UFRPE \\
T. viride LCB48 & TR2 & UFRPE \\
T. koningii LCB49 & T25 & UFRPE \\
T. polysporum LCB50 & SN11 & UFRPE \\
\hline
\end{tabular}

experimentos são apresentados na Tabela 1 e o tratamento controle recebeu apenas o formulante. Dez sementes por tratamento foram separadas para a contagem do número de conídios aderidos, com extração por agitação em solução de Triton X-100 0,05\% por 30 minutos a $120 \mathrm{rpm}$. Após diluição seriada decimal, $100 \mu \mathrm{l}$ da suspensão obtida foi transferida para meio Martin (WOLLUM II, 1982) para contagem do número de unidades formadoras de colônias.

Quatro sementes tratadas foram semeadas em potes contendo $3 \mathrm{dm}^{3}$ de uma mistura 3:1 de solo e areia, autoclavado por duas vezes a $121^{\circ} \mathrm{C}$ por 30 minutos, com intervalo de 24 horas entre as autoclavagens. Cinco dias após a germinação, as plantas em excesso foram cuidadosamente removidas de forma a atingir a uniformização do estande, permanecendo apenas uma planta por pote.

O delineamento experimental foi o de blocos inteiramente casualizados, com quatro repetições por tratamento e a parcela experimental composta de cinco plantas. O experimento teve duração de 30 dias e foi conduzido em casa de vegetação com ventilação forçada, localizada na Embrapa Semiárido (Petrolina, PE). Ao longo do experimento as plantas receberam nutrientes segundo resultado da análise de solo, equivalentes a 150 mg de N, $200 \mathrm{mg}$ de $\mathrm{P}_{2} \mathrm{O}_{5}$ e $100 \mathrm{mg}$ de $\mathrm{K}_{2} \mathrm{O}$ por vaso. Os vasos perfurados, com drenagem livre, foram mantidos com umidade em torno de $80 \%$ da máxima capacidade de retenção de água do substrato. Durante o período experimental monitorou-se a temperatura ambiental utilizando-se um termohigrógrafo obtendo-se uma média diurna de $28,5 \pm 2,7^{\circ} \mathrm{C}$ e média noturna de $23,2 \pm 3,2^{\circ} \mathrm{C}$.

Ao final do experimento a parte aérea foi colhida e procedeu-se a determinação da área foliar utilizando-se um integrador de bancada Licor (Licor Inc., USA). As amostras foram secas em estufa com circulação forçada a $65^{\circ} \mathrm{C}$ até atingir peso constante; a seguir, as raízes foram cuidadosamente removidas e gentilmente agitadas para remoção do excesso de substrato aderido. O material que permaneceu aderido às raízes foi considerado parte da rizosfera da planta. As raízes foram cortadas em fragmentos e transferidas para Erlenmayers contendo $100 \mathrm{~mL}$ de Triton $\mathrm{X}-100$ 0,05\%, que foram agitados por uma hora a $150 \mathrm{rpm}$ em mesa agitadora orbital (Quimis Ltda). A seguir, as raízes foram retiradas da suspensão, lavadas em água destilada e secas em estufa de circulação forçadas a $65^{\circ} \mathrm{C}$ por 72 horas. Diluições seriadas decimais da suspensão de material rizosférico foram plaqueadas em triplicata em BDA adicionado $25 \mathrm{mg} \mathrm{L}^{-1}$ de sulfato de estreptomicina e 25 $\mathrm{mg} \mathrm{L}^{-1}$ de cloreto de tetraciclina. As placas foram mantidas em incubadora BOD a $27^{\circ} \mathrm{C}$ no escuro e a contagem de colônias foi realizada após quatro dias de incubação em um contador de colônias de bancada. Os dados de contagem de propágulos foram transformados em $\log _{10}$ do número de unidades formadoras de colônias (UFC) por grama de raiz seca, alcançando-se distribuição lognormal (LOPER; SUSLOW; SCROTH, 1984). Os valores assim obtidos foram submetidos ao teste de $\mathrm{F}(\mathrm{p}<0,05)$ pela análise de variância (ANOVA) utilizando-se delineamento em blocos ao acaso, nos quais os valores observados para os blocos formados pela média das cinco plantas da parcela. As médias de contagem de UFC na rizosfera das plantas inoculadas com Trichoderma foram comparadas entre sí utilizando o teste de Tukey ( $\mathrm{p}<0,05)$, enquanto as variáveis de desenvolvimento vegetativo (área foliar, peso de raiz e de parte aérea) foram comparadas ao tratamento controle utilizando o teste de Dunnett.

O experimento de campo foi conduzido na estação experimental da Embrapa Semiárido localizado no Distrito Irrigado de Bebedouro (Petrolina, PE; 09 08'08' S, $40^{\circ}$ 18 '24" W) no período de abril a junho de 2008, em uma área de Argissolo Vermelho-Amarelo distrófico com textura média. Historicamente a área tem sido sucessivamente cultivada com oleráceas ao longo de quase 30 anos, resultando em alta infestação com patógenos. Uma avaliação prévia com o cultivo de meloeiro resultou em incidência elevada e homogeneamente distribuída de doenças de colo, ramos e raízes (superior a 50\%), com ocorrência de Fusarium oxysporum, Sclerotium rolfsii e Dydimella bryoniae.

As sementes foram tratadas com formulação de isolados de Trichoderma de forma similar ao descrito no experimento anterior e semeadas em substrato de germinação (Plantmax, Eucatex Agro Ltda) em bandejas de 128 furos, com uma semente por furo. Ao atingirem o primeiro folíolo definitivo (em torno de 7 dias após a germinação) as plântulas foram transferidas para o campo. 
O experimento foi conduzido em delineamento de blocos ao acaso com quatro repetições. As parcelas experimentais continham 32 plantas, emumespaçamento de $2,0 \times 0,5 \mathrm{~m}$ com irrigação por gotejamento, com gotejadores com vazão de $4 \mathrm{~L} \mathrm{~h}^{-1}$. A lâmina de irrigação foi estimada conforme descrito em Pinto et al. (1994), a partir de dados de evaporação de tanque Classe A e dados climáticos, obtidos em estação meteorológica automática (Campbell Inc.) instalada a $100 \mathrm{~m}$ da área experimental. As plantas receberam a aplicação de fertilizantes utilizando um sistema de fertirrigação, com o qual se distribuiu o equivalente a $100 \mathrm{~kg} \mathrm{ha}^{-1} \mathrm{de}$ $\mathrm{N}, 120 \mathrm{~kg} \mathrm{ha}^{-1}$ de $\mathrm{P}_{2} \mathrm{O}_{5}$ e $90 \mathrm{~kg} \mathrm{ha}^{-1}$ de $\mathrm{K}_{2} \mathrm{O}$, parcelado ao longo do ciclo conforme recomendação de Soares (1999). As fontes de nutrientes utilizadas foram fosfato monoamônio (MAP), uréia, ácido fosfórico $\left(\mathrm{H}_{3} \mathrm{PO}_{4}\right)$ e cloreto de potássio $(\mathrm{KCl})$, respectivamente. A incidência de doenças foi determinada por observações semanais do número de plantas sintomáticas, totalizando 11 avaliações ao longo do ciclo. Plantas apresentando sintomas de murcha ou necrose foram encaminhadas ao laboratório para a identificação do agente etiológico.

Ao completarem 73 dias os frutos apresentaram o ponto de maturação para colheita $\left({ }^{\circ}\right.$ Brix $\left.>9,0\right)$ e, neste período, se avaliou o estande efetivamente produtivo, o número e peso total de frutos e o número e peso de frutos comerciáveis. A normalidade da distribuição dos dados foi avaliada aplicando-se o teste de KolmogorovSmirnof e a homogeneidade da variância pelo teste de Levene. Os dados de incidência de doenças obtidos nas avaliações foram calculados em percentagem e, para fins de ANOVA, transformados utilizando-se a equação arcoseno $\left(\mathrm{x}_{\mathrm{ij}} / 100\right)$. As médias dos tratamentos com aplicação de Trichoderma foram comparadas com a media do tratamento controle utilizando teste de Dunnett. A eficácia (E\%), ou eficiência de controle da murcha pelos tratamentos, foi calculada utilizando-se a equação 1 :

$$
\mathrm{E} \%=\left\{1-\left[\mathrm{T}_{\mathrm{i}} / \mathrm{T}_{\mathrm{c}}\right]\right\} \times 100
$$

na qual: $\mathrm{E} \%=$ eficácia dos tratamentos; $\mathrm{T}_{\mathrm{i}}=\%$ média do estande final no tratamento $\mathrm{i} ; \mathrm{T}_{\mathrm{c}}=\%$ média do estande final no tratamento controle.

\section{RESULTADOS E DISCUSSÃO}

O tratamento das sementes resultou em colonização efetiva da rizosfera do meloeiro, encontrando-se variação significativa entre os isolados testados(Tabela2). As plantas inoculadas com $T$. viridae LCB48, T. koningii LCB49 e
T. harzianum LCB47 apresentaram o maior número de propágulos na rizosfera (Tabela 2) e estatisticamente similares entre si, diferindo significativamente (Tukey, $\mathrm{p}<0,05)$ de $T$. polysporum LCB50 com o menor número de unidades formadoras de colônias (UFC). Não foram detectados propágulos de Trichoderma no tratamento controle. Nas condições experimentais os tratamentos não interferiram no desenvolvimento das mudas, não diferindo significativamente do controle pelo teste de Dunnet $(\mathrm{P}>0,05)$ para o desenvolvimento de parte aérea e sistema radicular (Tabela 2 ).

O tratamento de sementes é um método atrativo para a aplicação do inóculo de microrganismos antagonistas para o controle de doenças. O tratamento de substrato, do solo ou a aplicação pela irrigação (fungicação) requerem uma grande quantidade de propágulos do ACB, aumentando os custos da operação. No entanto, para o controle efetivo de patógenos que atacam o sistema radicular utilizando o tratamento de sementes, o ACB deve possuir a capacidade de colonizar os possíveis sítios de infecção ao longo do rizoplano, apesar da competição com os microrganismos autóctones (WEERT; BLOEMBERG, 2006).

Desde os estudos de Papavizas (1985), uma série de evidências levou a crer que espécies de Trichoderma não são competentes para colonizar a rizosfera das plantas quando aplicadas por tratamento de sementes (AHMAD; BAKER, 1987; CHET, 1987). Até então poucas exceções haviam sido observadas, entre estas os casos de cultivo em substrato autoclavado ou mutantes especificamente desenvolvidos para a colonização da rizosfera de algumas plantas (LO et al., 1998; SIVAN; CHET, 1989). Além do mais, os resultados de contagem em cultivo em meio de cultura podem não refletir o estado da atividade dos fungos antagonistas no solo ou rizosfera (AHMAD; BAKER, 1987).

Por outro lado, Ethur et al. (2008) mostraram a ocorrência espontânea de fungos do gênero Trichoderma em solo da rizosfera de tomateiro e pepineiro em áreas sob cultivo contínuo destas culturas. Além disto, quando aplicado através do revestimento de sementes T. harzianum T3a colonizou ativamente o tegumento e resíduos de sementes de diferentes plantas (GREEN et al., 2001), o que lhe permitiu maior capacidade para a proteção das sementes e das radículas emergentes. Green e Jensen (1995) detectaram a colonização de sítios específicos ao longo do rizoplano por cepas de Trichoderma, principalmente as pequenas feridas formadas pela abrasão com o solo (ou substrato) e em pontos de emergência de raízes secundárias. Estes danos são comuns ao longo do desenvolvimento do sistema radicular e esta característica torna-se importante para agentes de controle biológico, promovendo a proteção de possíveis sítios de infecção. 
Tabela 2 - Efeito do tratamento de sementes de meloeiro amarelo AF682 com conídios de T. harzianum LCB47, T. viride LCB48, T. koningii LCB49 e T. polysporum LCB50 sobre o desenvolvimento da área foliar, massa da parte aérea seca, massa de raízes secas e a colonização da rizosfera de plantas cultivadas em casa de vegetação (Petrolina - PE, 2008)

\begin{tabular}{lcccc}
\hline \multirow{2}{*}{ Tratamentos } & Área foliar & Raiz & Parte aérea & Colonização \\
\cline { 2 - 5 } & $\left(\mathrm{cm}^{2}\right.$ planta $\left.^{-1}\right)$ & $\left(\mathrm{g} \mathrm{planta}^{-1}\right)$ & $\left(\mathrm{g} \mathrm{planta}^{-1}\right)$ & $\left(\mathrm{UFC}^{-1} \mathrm{raiz}^{2}\right.$ \\
\hline Controle & $472,0(114,1)$ & $3,40(0,99)$ & $3,96(0,57)$ & $\mathrm{ND}^{2}$ \\
T. harzianum LCB47 & $477,4(80,3)^{\mathrm{NS} 1}$ & $3,24(0,61)^{\mathrm{NS}}$ & $3,36(0,51)^{\mathrm{NS}}$ & $4,54(0,64) \mathrm{a}^{3}$ \\
T. viride LCB48 & $503,9(76,6)^{\mathrm{NS}}$ & $3,67(0,74)^{\mathrm{NS}}$ & $4,11(0,55)^{\mathrm{NS}}$ & $5,81(0,54) \mathrm{a}$ \\
T. koningii LCB49 & $499,1(70,1)^{\mathrm{NS}}$ & $3,55(0,64)^{\mathrm{NS}}$ & $3,94(1,18)^{\mathrm{NS}}$ & $5,66(0,39) \mathrm{a}$ \\
T. polysporum LCB50 & $475,3(60,0)^{\mathrm{NS}}$ & $3,20(0,59)^{\mathrm{NS}}$ & $3,46(0,54)^{\mathrm{Ns}}$ & $3,27(1,88) \mathrm{b}$ \\
CV \% & 12,1 & 17,8 & 32,1 & 21,8 \\
\hline
\end{tabular}

${ }^{1}$ Médias seguidas de NS não se diferenciam do tratamento controle pelo teste de Dunnett $(\mathrm{p}<0,05) .{ }^{2} \mathrm{ND}=$ não detectado. ${ }^{3}$ Médias seguidas da mesma letra na coluna não diferem estatisticamente entre si de acordo com o teste de Tukey $(\mathrm{p}<0,05)$

O experimento em campo para avaliação da eficiência de controle foi conduzido entre os meses de abril a junho de 2009, com umidade do ar e ocorrência de períodos de instabilidade pluviométrica e precipitações característicos do período para a região (Figura 1).

Figura 1 - Variáveis meteorológicas - Temperatura máxima ( $\mathrm{T}$ max), Temperatura mínima ( $\mathrm{T}$ min), Temperatura média ( $\mathrm{T}$ média) e precipitação observadas durante o período experimental para a avaliação do controle de patógenos do solo por isolados de Trichoderma na cultura do meloeiro na Estação Experimental de Bebedouro da Embrapa Semiárido entre 17/04 e 29/06/2008 (Petrolina-PE)

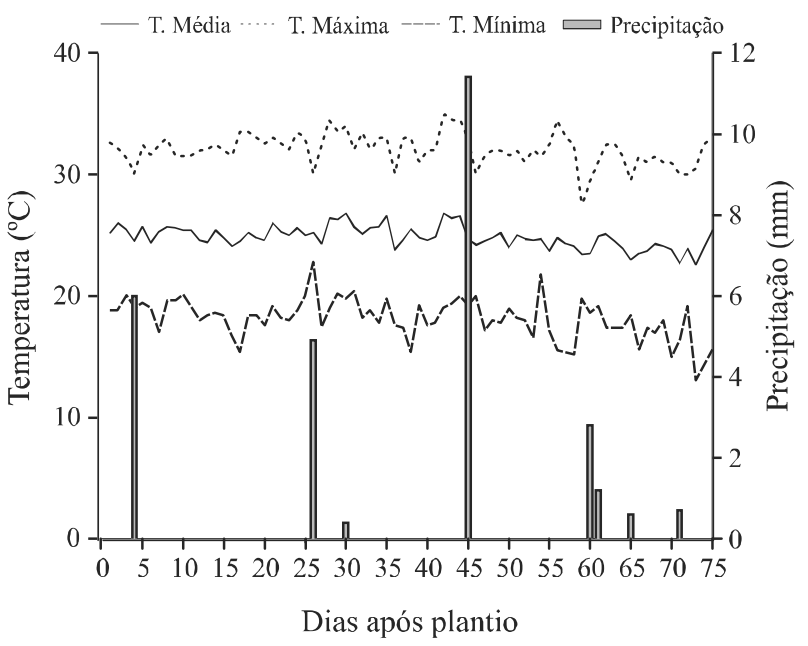

Após sete dias do transplantio foram observadas plantas mortas, contudo nenhum agente patogênico foi associado a essas plantas, sendo portanto consideradas mortas em função de danos mecânicos nas operação do transplantio. $\mathrm{Na}$ avaliação realizada aos 32 DAP verificou-se que $46,6 \%$ das plantas do tratamento controle apresentavam sintomas, enquanto que o tratamento com os isolados LCB49 e LCB50 apresentavam uma taxa de mortalidade média de 25,7 e $28,6 \%$, respectivamente (Figura 2). Neste período, o isolado LCB48 apresentou perda média de estande de $36,1 \%$, valor similar ao observado no tratamento com LCB47 (40,8\%) e ao controle. Na terceira avaliação (47 dias) os resultados mantiveram-se estáveis em relação a anterior, exceto para o tratamento com o isolado LCB48 que apresentou ligeira elevação na taxa de incidência de murcha das plantas (Figura 2).

Figura 2 - Incidência de murcha ao longo do ciclo do meloeiro amarelo AF682 cultivado em área com elevada taxa de ocorrência natural causadas por patógenos de solo (Petrolina-PE, 2008)

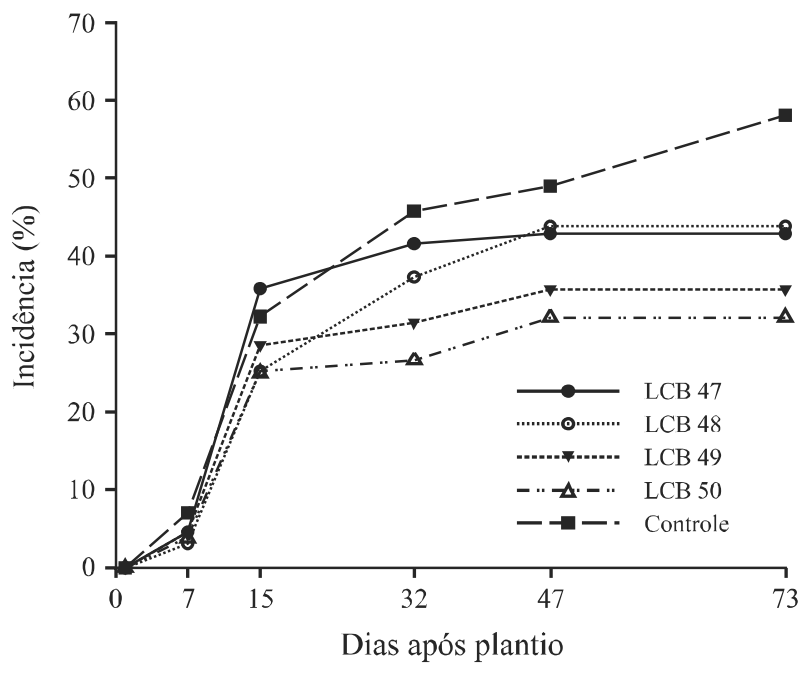


$\mathrm{Na}$ avaliação final do estande, realizada na colheita do experimento aos 73 DAP, verificou-se que todos os tratamentos com os isolados de Trichoderma apresentaram perda no estande inferior ao controle (Tabela 3), conforme teste de Dunnett $(\mathrm{p}<0,05)$. Os tratamentos com os isolados LCB49 e LCB50 apresentaram os melhores resultados quanto à sobrevivência e ao número de plantas efetivamente em produção (Tabela 3). Por outro lado, os tratamentos com os isolados LCB47 e LCB48 apresentaram resultados estatisticamente similares entre si e diferentes dos obtidos com o tratamento controle (Dunnett, $\mathrm{p}<0,05$ ).

Verificou-se que, de forma geral, a aplicação dos isolados de Trichoderma resultou em redução significativa da incidência de murchas do meloeiro. Ao final do experimento (73 dias) os tratamentos com os isolados LCB49 e LCB50 apresentaram a maior eficácia de controle da murcha, com 48,1 e 51,6\%, respectivamente (Tabela 3). Estes resultados são similares aos encontrados por Tavares et al. (2001) e Batista et al. (2002) para o controle de doenças na cebola, maracujá e tomate no Vale do São Francisco.

A análise das plantas sintomáticas em laboratório mostrou que o principal agente causal de tombamento e morte das plantas até 15 DAP foi Sclerotium rolfsii (87,0\%). A partir de então e até 32 DAP (período de floração) verificou-se a ocorrência de $S$. rolfsii, Fusarium solani e $F$. oxysporum entre as plantas com sintomas de murcha. A partir de $32 \mathrm{DPA}$ até a colheita $F$. oxysporum foi o principal agente causal da murcha observada nas plantas. Embora a área apresentasse histórico prévio de incidência do fungo Macrophomina phaseolina, não foram observadas plantas com sintomas associados a este patógeno durante a realização do experimento.

A variabilidade na eficácia de controle das diferentes espécies de Trichoderma avaliadas pode estar associada às suas características intrínsecas como a habilidade de sobrepujar os mecanismos de defesa dos patógenos, competir com microrganismos do solo e resistir aos fatores abióticos no solo (COOK, BAKER, 1983). Bae e Knudsen (2005), por exemplo, demonstraram que solos com elevada população microbiana apresentaram menor crescimento da população de Trichoderma harzianum. Este efeito está fortemente associado à composição da comunidade microbiana, em particular à presença de bactérias do gênero Pseudomonas, conhecidas por sua habilidade para produção de antibióticos e sideróforos (DE BOER et al., 2003).

A menor competência rizosférica também pode ser um dos fatores de baixa eficiência de controle, contudo os resultados deste trabalho apresentaram baixa associação com os dados de colonização da rizosfera verificados no experimento anterior. O isolado LCB50 apresentou o menor número de propágulos na rizosfera, como pode ser observado na Tabela 1 , apresentando taxa de controle da incidência de murcha similar ao LCB49 que, por sua vez, mostrou alta densidade de propágulos na rizosfera $\left(3,27 \pm 1,88\right.$ e 5,66 $\pm 0,39 \mathrm{UFC} \mathrm{g}^{-1}$ raiz, respectivamente). Contudo, como verificado por Bae e Knudsen (2005), fatores bióticos e abióticos podem reduzir o crescimento da população de Trichoderma no solo, mas uma maior capacidade antagonista, como a produção de antibióticos e competição com os patógenos, pode ter resultado em maior eficácia.

Agentes de controle biológico capazes de colonizar efetivamente a rizosfera proporcionam proteção das raízes, eliminando propágulos de patógenos ou competindo pelos nutrientes existentes. Principalmente no caso dos fungos do gênero Trichoderma, que têm elevada capacidade saprofítica. Uma vez que $T$. polysporum LCB50 caracterizase pela baixa produção de conídios, com extensivo crescimento de micélio estéril (SAMUELS et al., 2008), é possível que o maior número de propágulos detectados na rizosfera das plantas tratadas com os demais isolados seja resultado da produção de conídios na rizosfera ou o carreamento pela água, não representando adequadamente a biomassa acumulada.

Tabela 3 - Sobrevivência, eficácia dos tratamentos e produção de frutos comerciais de meloeiro amarelo AF682 em experimento com o revestimento de sementes com formulação de quatro isolados de Trichoderma spp. em uma área com elevada incidência natural de murcha do meloeiro (Petrolina-PE, 2008)

\begin{tabular}{lccc}
\hline \multirow{2}{*}{ Tratamentos } & Sobrevivência & Eficácia & Produção \\
\cline { 2 - 4 } & $(\%)$ & $(\mathrm{E} \%)$ & $\left(\mathrm{Mg} \mathrm{ha}^{-1}\right)$ \\
\hline Controle & 47,001 & - & 13,8 \\
T. harzianum LCB47 & $67,19^{*}$ & 42,96 & $18,3^{*}$ \\
T. viride LCB48 & $62,50^{*}$ & 32,98 & $17,8^{*}$ \\
T. koningii LCB49 & $69,62^{*}$ & 48,13 & $21,4^{*}$ \\
T. polysporum LCB50 & $71,25^{*}$ & 51,60 & $23,2^{*}$ \\
\hline
\end{tabular}

Médias apresentando asteriscos $(*)$ diferem significativamente do controle na mesma coluna pelo teste de Dunnett $(\mathrm{p}>0,05)$ 
Por outro lado, estes resultados podem estar refletindo uma maior adaptação do LCB50 e do LCB49 aos fatores bióticos e abióticos encontrados nas condições experimentais, não permitindo descartar a importância da colonização rizosférica pelos ACB para a eficiência do controle de doenças. Outros fatores intrínsecos aos isolados podem estar associados à sua maior eficiência de controle, como a produção de metabólitos antibióticos, produção de enzimas líticas e a eficiência na competição com a microbiota nativa. Além disso, não é possível desprezar as limitações das técnicas empregadas e novos estudos estão em andamento para a seleção de mutantes naturais resistentes a fungicidas objetivando novos estudos de colonização da rizosfera em condições de solo não autoclavado.

\section{CONCLUSÃO}

A partir dos resultados conclui-se que, nas condições experimentais, os isolados de Trichoderma spp. colonizaram ativamente a rizosfera das plantas, apresentando variação entre as espécies estudadas. De forma similar, todos os isolados apresentaram controle significativo da ocorrência de tombamento e murcha de plantas de meloeiro. No entanto, o tratamento de sementes com os isolados de T. koningii LCB49 e $T$. polysporum LCB50 proporcionou, ao final do experimento, maior estande de plantas quando comparado com o tratamento controle e, conseqüentemente, levou à maior produção de frutos em toneladas $\mathrm{ha}^{-1}$.

\section{AGRADECIMENTOS}

Os estudos foram co-financiados pela Empresa Brasileira de Pesquisa Agropecuária - Embrapa e o Fundo de Desenvolvimento Científico do Banco do Nordeste Brasileiro. Agradecemos ainda a Ernando Ferreira Mota, Assistente de Pesquisa da Embrapa Semiárido, pelo apoio técnico na realização dos experimentos.

\section{REFERÊNCIAS}

AHMAD, J. S.; BAKER, R. Induction of rhizosphere competence in Trichoderma harzianum. Phytopathology, v. 75, n. 11, p. 1302, 1987.

BAE, Y. S.; KNUDSEN, G. R. Soil microbial biomass influence on growth and biocontrol efficacy of Trichoderma harzianum. Biological Control, v. 32, n. 02, p. 236-242, 2005.

BATISTA, D. C. et al. Efeitos de fungicidas inibindo o crescimento in vitro de Fusarium oxysporum f. sp. passiflorae e interferência com Trichoderma spp. Summa Phytopathologica, v. 28 , n. 04 , p. $305-310,2002$.
BUTT, T. M.; JACKSON, C.; MAGAN, N. Fungi as biocontrol agents: Progress, Problems and Potential. Wallingford, UK: CAB International, 2001. 390 p.

CHINCHOLKAR, S. B.; MUKERJI, K. G. (Ed.) Biological control of plant diseases. New York: Haworth Press, 2007. 270 p.

CHET, I. Trichoderma - application, mode of action, and potential as a biological control agent of soilborne plant pathogenic fungi. In: CHET, I. Innovative approaches to plant disease control. New York: John Wiley, 1987. cap. 5, p. 127-160.

COOK, R. J.; BAKER. K. F. The nature and practice of biological control of plant pathogens. 2. ed. St. Paul: APS Press, 1983. 539 p.

DE BOER, W. et al. Microbial community composition affects soil fungistasis. Applied Environmental Microbiology, v. 69, n. 02, p. 835-844, 2003.

EL-HASAN,A.;WALKER,F.; BUCHENAUER, H.Trichoderma harzianum and its metabolite 6-pentyl-alpha-pyrone suppress fusaric acid produced by Fusarium moniliforme. Journal of Phytopathology, v. 156, n. 02, p. 79-87, 2006.

EL-TARABILY, K. A. Rhizosphere-competent isolates of streptomycete and non-streptomycete actinomycetes capable of producing cell-wall-degrading enzymes to control Pythium aphanidermatum damping-off disease of cucumber. Canadian Journal of Botany, v 84, n. 21, p. 211-222, 2006.

ETHUR, L. Z. et al. Presença dos gêneros Trichoderma e Fusarium em solo rizosférico e não rizosférico cultivado com tomateiro e pepineiro, em horta e estufa. Ciência Rural, v. 38 , n. 01 , p. $19-26,2008$.

GREEN, H.; JENSEN, D. F. A tool for monitoring Trichoderma harzianum: II. The use of a GUS transformant for ecological studies in the rhizosphere. Phytopathology, v. 85, n. 11, p. 1436-1440, 1995.

GREEN, H.; HEIBERG, N.; LEJBØLLE, K.; JENSEN, D. F. The use of a GUS transformant of Trichoderma harzianum, strain T3a, to study metabolic activity in the spermosphere and rhizosphere related to biocontrol of Pythium damping-off and root rot. European Journal of Plant Pathology, v. 107, n. 03, p. 349-359, 2001.

HARMAN, G. E. Overview of mechanisms and uses of Trichoderma spp. Phytopathology v. 96, n. 02, p. 190-194, 2006.

HARMAN, G. E. et al. Changing models for commercialization and implementation of biocontrol in the developing and the developed world. Plant Disease, v. 94, n. 08, p. 928-939, 2010.

LO, C. T. et al. Ecological studies of transformed Trichoderma harzianum strain 1295-22 in the rhizosphere and on the phyloplane of creeping bentgrass. Phtyopatology, v. 88, n. 02, p. 129-136, 1998.

LOPER, J. E.; SUSLOW, T. V.; SCROTH, M. N. Lognormal distribution of bacterial population in the rhizosphere. Phytopathology, v. 74, p. 1454-1466, 1984.

MCLEAN, K. L. et al. Effect of formulation on the rhizosphere competence and biocontrol ability of Trichoderma atroviride C52. Plant Pathology, v. 54, n. 02, p. 212-218, 2005. 
MEDEIROS, E. V. et al. Quantificação de Ascósporos de Monosporascus cannonballus em solos não cultivados de Caatinga e em áreas de cultivo de Melão do Rio Grande do Norte e Ceará. Fitopatologia Brasileira, v. 31, n. 05, p. 500-504, 2006.

MIRANDA, M. E. A.; ESTRELLA, A. H.; CABRIALESA, J. J. P. Colonization of the rhizosphere, rhizoplane and endorhiza of garlic (Allium sativum L.) by strains of Trichoderma harzianum and their capacity to control allium white-rot under field conditions. Soil Biology and Biochemistry, v. 38, n. 07, p. 1823-1830, 2006.

PAPAVIZAS, G. C. Trichoderma and Gliocladium: Biology, Ecology, and Potential for Biocontrol. Annual Review of Phytopathology, v. 23, p. 23-54, 1985.

PINTO, J. M. et al. Efeitos de periodos e de frequencias da fertirrigacao nitrogenada na producao do melao. Pesquisa Agropecuaria Brasileira, v. 29, n. 09, p. 1345-1350, 1994.

SAMUELS, G. J. et al. Trichoderma online - Systematic mycology and microbiology laboratory, ARS, USDA. 2008. Disponível em: <http://nt.ars-grin.gov/taxadescriptions/keys/ TrichodermaIndex.cfm>. Acesso em: 22 jul 2011.

SIVAN, A.; CHET, I. The possible role of competition between Trichoderma harzianum and Fusarium oxysporum on rhizosphere colonization. Phytopathology, v. 79, n. 02, p. 198-203, 1989.

SOARES, J. M. Fertirrigação na Cultura do Meloeiro. Petrolina: Embrapa Semiárido, 1999.

TAVARES, S. C. C. de H. Mix de. Trichoderma spp. como antagonista e promotor de crescimento em feijoeiro na região semiárida do vale do Sao Francisco. In: CONGRESSO BRASILEIRO DE FITOPATOLOGIA,32.,1999, Curitiba. Fitopatologia Brasileira, v. 24, p. 337, 1999. Suplemento.
TAVARES, S. C. C. de H. Mix de Trichoderma spp. no controle biológico de hortifrutíferas no Semiárido brasileiro. In: REUNIÃO NACIONAL DE CONTROLE BIOLÓGICO DE FITOPATÓGENOS, 7., 2001, Bento Gonçalves. Anais... Bento Gonçalves: Embrapa Uva e Vinho, 2001. p. 78.

UBALUA, A. O.; Oti, E. Antagonistic properties of Trichoderma viride on post harvest cassava root rot pathogens. African Journal of Biotechnology, v. 06, n. 21, p. 2447-2450, 2007.

WEERT, S.; BLOEMBERG, G. V. Rhizosphere competence and the role of root colonization in biocontrol. In.: GNANAMANICKAM, S. (Ed.) Plant-Associated Bacteria. Dordrecht: Springer, 2006. cap. 2, p. 317-333.

WHIPPS, J. M. Microbial interactions and biocontrol in therhizosphere. Journal Experimental Botany, v. 52, n. 03, p. 487-511, 2001.

WOLLUM II, A. G. Cultural methods for soil microorganisms. In: MILLER, R. H.; KEENEY, D. R. Methods of soil analysis: chemical and microbiological properties. Madison: Soil Science of American, 1982. cap. 5, p. 781-802.

YEDIDIA, I. et al Concomitant Induction of Systemic Resistance to Pseudomonas syringae pv. lachrymans in cucumber by Trichoderma asperellum ( $\mathrm{t}-203)$ and accumulation of phytoalexins. Applied Environmental Microbiology, v. 69, n. 12, p. 7343-7353, 2003.

ZAYED, G.; ABDEL-MOTAAL, H. Bio-active composts from rice straw enriched with rock phosphate and their effect on the phosphorous nutrition and microbial community in rhizosphere of cowpea. Bioresource Technology v. 96, n. 08, p. 929-35, 2005. 